\title{
Concept Design of a Digital Shop Floor Information System for Assembly Operators in Machine Industry
}

\author{
Matthias Tauber ${ }^{1}$, Andreas Gallmetzer ${ }^{1}$, Erwin Rauch ${ }^{1,}$, Christopher A. Brown ${ }^{2}$ and Dominik T. Matt ${ }^{1,3}$ \\ ${ }^{1}$ Free University of Bolzano, Faculty of Science and Technology, Industrial Engineering and Automation (IEA), 39100 Bolzano, Italy \\ ${ }^{2}$ Worcester Polytechnic Institute, Department of Mechanical Engineering, 01609 Worcester, MA, USA \\ ${ }^{3}$ Fraunhofer Italia Research s.c.a.r.l., Innovation Engineering Center, 39100 Bolzano, Italy
}

\begin{abstract}
Industry 4.0 and digitization are currently changing shop floor management in production. Especially in the production of highly customized and individual products, digitization offers many opportunities for more efficient processes. Providing the right information in the right time at the right place can help to reduce lead time as well as production costs. This paper shows the use of Axiomatic Design to develop a conceptual design for an innovative and digital shop floor information system for supporting assembly operators in machine industry in their daily work. The research is based on a real industrial case study with a medium sized manufacturer of customized machines. Needs from practice were collected through workshops with the industry partner and were translated into functional requirements. These functional requirements were derived with an Axiomatic Design decomposition to design solutions. The results of the $\mathrm{AD}$ analysis were used as a basis for the concept design of an operator information system in the company.
\end{abstract}

\section{Introduction}

The main challenges for small and medium-sized enterprises (SMEs) in the coming years include increasing quality requirements, wide-range production diversity down to batch size one, managing the complexity of production processes and reduce lead time as well as production costs [1]. Due to these growing demands on companies, the concept of rigid production must be reconsidered in several aspects. This is where Industry 4.0 comes in. In some ways, there are similarities between Industry 4.0 and Lean Management [2]. Both try to counteract problems at an early stage through continuous improvement, better data acquisition and control principles and to act in a resource-saving manner [3]. By superimposing IT systems embedded in cyber-physical systems (CPS), self-regulating processes and networking of the horizontal and vertical value chain can be achieved [4]. At the same time, networking enables digitally integrated engineering throughout the entire value chain [5].

This work aims to improve the mutual communication within the value chain. To enhance this interface, a concept for a digital shop floor information system for assembly operators is developed. This is a step towards digitally integrated engineering, where horizontal and vertical integration are some of the fundamental characteristics of Industry 4.0 [5].

In doing so, the individual value-added processes (production, engineering design, logistics, etc.) are to be combined via IT solutions into a holistic value chain. The aim is to transfer knowledge in the value chain as lossfree as possible and without redundant work steps (according to Lean principles). In addition to the main transfer of information, which follows the process direction, the opposite direction mapping affiliated to the information system, beyond doubts contributes significantly to the value creation [6].

This research is based on a comprehensive analysis of the current situation, in which a map of the current knowledge transfer is recorded by means of "Collaboration Stream Mapping" [7]. Paying attention to the optimization potential, Axiomatic Design (AD) is used to develop a catalogue of functional requirements for the system design. The catalogue of functional requirements and the design fields defined with $\mathrm{AD}$ serve as base for the determination of the target state, which is conceived via a Future Collaboration Map. The paper concludes with the description of this target state and a digital mock-up, which serves as basis for the implementation of the digital shop floor information system in an industrial SME company.

\section{Theoretical Background}

A brief explanation of the term 'Industry 4.0' illustrates the broad spectrum of new opportunities for companies: after the mechanization, the electrification and the computerization, Industry 4.0 marks the fourth industrial revolution, including several major topics such as Big Data, Internet of Things (IoT), Smart Products, Smart Operations and Smart Factory. This paper deals with the topic Smart Factory, more precisely with following two issues: digital integrated engineering and digital shop

*Corresponding author: $\quad$ Erwin.Rauch@unibz.it 
floor management. Both terms are described in the following two subchapters.

\subsection{Integrated Engineering}

In order to gain added value from a networked value chain, the purely physical link of intertwined departments is not enough, so that the need for consistent and lossless data transfer arises. The explicated concept is apprehended in the industrial environment as the quintessence of digital integrated engineering [6].

The term engineering is defined in this paper as "the branch of science and technology concerned with the design, building, and use of engines, machines, and structures" [8].

\subsection{Digital Shop Floor Management}

Shop floor management is a production control instrument, whose purpose consists of enabling process improvement, identification of deviations, and structured problem solving directly on the production shop floor [9].

The enhancing digitization affects traditional Lean shop floor management systems by exposing them to variegated new influences. As a result, in the near future data transmission and evaluation occur in real-time through advanced capabilities of area-wide sensors, data capturing and smart processes [10].

The substance of the digital shop floor management entails three elements, which are defined as follows:

\section{Data Collection:}

Data originates from different systems, such as Enterprise Resource Planning (ERP), Customer Relationship Management (CRM) or Manufacturing Execution System (MES) [11]. Even though the cited systems have been conceived and adopted before the conceptualization of "smart factory", the essential idea of production-related data processing appears to remain in force [12].

2. Data Management:

The potentiality attributable to data is reaffirmed in industrial environment each day anew. A prime instance in this regard is epitomized by the quality improvement procedure. In order to exploit synergistical dynamics, the cross-linking of diverse data typologies, such as the recorded process data and the quality management data, is fostered. A concrete result is the facilitated localization of quality defects and tolerance limits, whose degree of precision is enhanced by the continuous elaboration of stored data [11].

3. Production Management:

Climbing the implication ladder up, the subsequent level, respectively represented by the production sphere is tackled. Leaning on the previously explicated instance, the tolerances deviations from the base for possible as well as necessary real-time readjustments or changeovers. Such measures guarantee constant and instantaneous process improvement and learning through mistakes [11].
However, the benefits of the processes shown can only be used if all affected processes and departments are integrated by the use of shared or common systems [13]. This linking can be achieved with integrated engineering.

In this light, the conception of the digital shop floor information system follows the attempt to concretize the above-mentioned beneficial effects.

\section{Problem Formulation and Case Study Description}

In this work, case study research has been chosen as research methodology. For the concept development of the digital shop floor information system AD was used as a development method. AD was chosen as the development method, since it enables the developer to capture all necessary requirements and to incorporate them into the design concept. The case study approach on the other hand ensures that the concept can be successfully implemented and used in SME practice. The method, the concrete use case and the research goals are explained in this chapter.

\subsection{Industrial Case Study - Assembly in Machine Industry}

The research is based on a real industrial case with a medium-sized manufacturer of special machines in the North of Italy. This research method combines several qualitative and quantitative methods (e.g., interviews, workshops, observations) for data collection. Thanks to the different collection methods, a flexible data collection can be carried out, in which the respective advantages of the individual methods take effect [14].

The case study is particularly suitable for this investigation as the manufacturing company is currently suffering of a not optimized and not well working transfer of information between the engineering, quality management and production department as well as between assembly operators in production itself.

\subsection{Research Objectives}

The main objective of the work is to design an innovative digital shop floor information system by using $\mathrm{AD}$ as development method. Through the structured design approach of $\mathrm{AD}$, whereby the developer moves through four domains a design concept for a digital shop floor information system should be created. By introducing the tool into practice, the mutual communication between the departments will be improved. Thus, shop floor process will be made more efficient.

\section{Methodology}

This chapter introduces the core method of the development process, which is AD.

Axiomatic Design is a design theory developed at the Massachusetts Institute of Technology (MIT) in the 
seventies. The founder of the method is Nam Pyo Suh [15].

According to Suh, design is an interplay between two central questions:

„Design is an interplay between WHAT we want to achieve and HOW we want to achieve it " [15, p. 10].

To systematize this interplay into a thinking process, AD uses the following four domains.

- Customer domain: The customer domain expresses the customer needs (CNs).

- Functionaldomain: The functional domain describes the functional requirements (FRs) and non-functional requirements (n-FRs) of the system. These requirements are derived from the previously defined CNs. In addition, system constraints (Cs) are defined.

- Physical domain: The physical domain contains the design parameters (DPs) of the system that should meet the previously defined functional requirements.

- Process domain: Finally, in the last domain, the process domain, the design parameters (DPs) are transformed into real process variables (PVs).

The choice between different design parameters is based on the two axioms (Axiom 1-Independence Axiom and Axiom 2 - Information Axiom), which form the core of AD. According to Suh, a design is good if it fulfils both axioms:

- Axiom 1 - Independence Axiom: The system design is ideal when all FRs are fulfilled independently. An ideal design is therefore characterized if each DP satisfies only one FR and does not affect the other FRs [16].

- Axiom 2-Information Axiom: The information axiom offers the designer the opportunity to choose the best design parameter among several possible options. In the process, the design parameter with the lowest information content should be selected. The intent of this axiom is to minimize the information content of the system design and to select the simplest solutions, as this ensures the highest probability of success. Axiom 2 can be summarized with the well-known design concept KISS ('keep it simple and smart') [16].

\section{Axiomatic Design of a Digital Shop Floor Information System for Assembly}

In the development process of the Digital Shop Floor Information System AD is used to derive a catalogue of FRs, which are then transferred into DPs and thus design guidelines for the desired shop floor information system.

This chapter shows the application of the AD approach; starting from the CNs and ending with the design tree containing low-level FR-DP pairs.

\subsection{Collection of Customer Needs}

The first step in the application of $\mathrm{AD}$ is the collection of the CNs. Since with a simple interview with the process owners there is a risk of subjectivity, a more detailed approach was chosen, namely an analysis of the current information flows in the shop floor. The method used is Collaboration Stream Mapping (CSM). The aim of this value stream-oriented approach is to visualize the cooperation and knowledge transfer between departments in the company [7].

In addition to the recording of all information flows in the Current Collaboration Map (CCM), first optimization potentials of the information system were also noted, so-called Kaizen bursts.

The optimization potentials (Kaizen bursts) identified in the CCM describe the problems of the current system. From these, the system characteristics of the system to be developed could be derived. Therefore, the first step in the development of the $\mathrm{CNs}$ was the translation of the optimization potentials into single needs. By looking more closely to the outcome of this process it could be obtained, that multiple needs are similar. For this reason, the various $\mathrm{CNs}$ were categorized together with the team from the SME and summarized. In addition, the team defined the core requirement of the new system $\left(\mathrm{FR}_{0}\right)$ from the reduced and more general list of CNs.

This categorization process was performed by a qualitative assessment of each individual need. If similarities in the wording or the same keywords were identified, the $\mathrm{CN}$ fell into the same group. The entire process of the collection of the $\mathrm{CNs}$ is summarized in Figure 1.

The result of this operation are the following four $\mathrm{CNs}$ that mark the starting point of the $\mathrm{AD}$ application:

- $\mathrm{CN}_{1}$ : Need for a central folder of assembly documents and information.

- $\mathrm{CN}_{2}$ : Recording, feedback and evaluation of problems, documents and information during assembly and installation process.

- $\mathrm{CN}_{3}$ : Alternative system for the communication between the departments.

- $\mathrm{CN}_{4}$ : Simple intuitive recording of processing times during assembly and installation. 

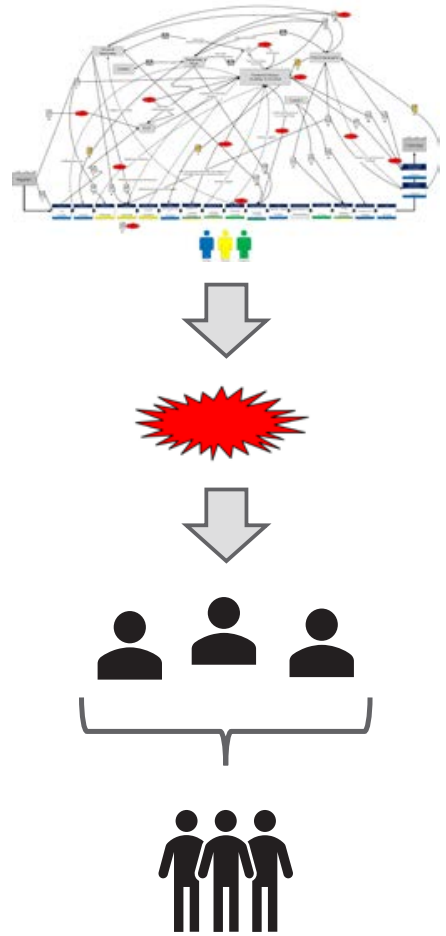

FR0 - DP0

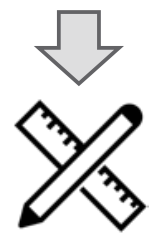

Figure 1: Collection of the Customer Needs (CNs)

\subsection{Definition of Top-Level FR-DP-pairs}

After the main list of CNs has been worked out, the core functional requirement $\left(\mathrm{FR}_{0}\right)$ is formed. The core requirement is defined as follows:

- $\quad \mathrm{FR}_{0}$ : Collect and provide the right information for the right user.

DP0 is defined as follows:

- $\quad \mathrm{DP}_{0}$ : Worker Information system.

After defining FR0 and DP0, Cs and n-FRs of the system are determined. These limitations should be considered in the design process by the designer. Following there are the defined Cs and n-FRs for the digital shop floor information system:

- $\quad \mathrm{C}_{1}$ : The information system must be based on a software solution (digitalization and paperless work in the production shop floor).

- $\mathrm{C}_{2}$ : The information system must have an interface to SAP (as this is the ERP system used in the case study company).

- $\quad \mathrm{C}_{3}$ : The information system must be compatible with mobile devices.
- n-FR 1 All information streams should be digitized.

- $\quad \mathrm{n}-\mathrm{FR}_{2}$ : The system design should be based on a single software solution.

After the development of FR0 and DP0, which prove to be very abstract, the decomposition process (zigzagging) takes place. The decomposition of FR0-DP0 provides the following partial requirements:

- $\quad \mathrm{FR}_{1}$ : Gather information.

- $\quad \mathrm{FR}_{2}$ : Record, evaluate and send a feedback of problems during the assembly process.

- $\quad \mathrm{FR}_{3}$ : Communicate with other departments.

- $\mathrm{FR}_{4}$ : Monitor the working hours in the assembly process.

- $\quad \mathrm{FR}_{5}$ : Represent correct information.

The corresponding DPs for fulfilling the FRs are listed in the following enumeration:

- $\quad \mathrm{DP}_{1}$ : Document Management System.

- $\mathrm{DP}_{2}$ : Workflow System.

- $\mathrm{DP}_{3}$ : Communication System.

- $\mathrm{DP}_{4}$ : Working Hours Monitoring System.

- $\mathrm{DP}_{5}$ : Graphical User Interface.

The DM on the first level is classified as decoupled and thus represents a good system design. The decoupled matrix defines the system to be path-dependent, which means that the correct sequence in the implementation is necessary to avoid circular references and thus to reduce complexity.

$$
\left\{\begin{array}{l}
F_{1} \\
F_{2} \\
F_{3} \\
F_{4} \\
F R_{5}
\end{array}\right\}=\left[\begin{array}{lllll}
X & 0 & 0 & 0 & 0 \\
X & X & 0 & 0 & 0 \\
0 & 0 & X & 0 & 0 \\
O & 0 & 0 & X & 0 \\
X & X & X & X & X
\end{array}\right]\left\{\begin{array}{l}
D_{1} \\
D_{2} \\
D_{3} \\
D_{4} \\
D P_{5}
\end{array}\right\}
$$

Figure 2 shows the FR-DP tree of the highest hierarchical level:

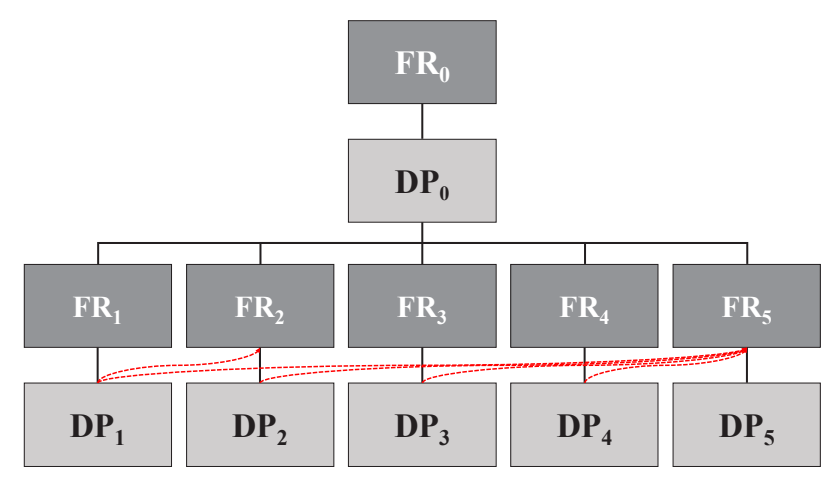

Figure 2: FR-DP tree at first level (according to the graphical visualization introduced by Cochran et al. [18]) 


\subsection{Decomposition and Mapping}

After the formulation of the top-level FR-DP tree it is necessary to decompose the still generally formulated and abstract requirements into more tangible parameters.

The decomposition process is initiated on the basis of the hierarchically highest requirement. This top-down approach divides each FR into sub-requirements. Where for each sub-requirement a matching DP is assigned.

This process is carried out until enough concrete and implementable design solutions have been developed. For a better understanding, the individual FR-DP pairs are listed and described in the following sections.

\subsubsection{FR1-DP1 Digital Assembly Folder}

The digital assembly folder forms the core of the digital shop floor information system and is a collection of all the information needed for the assembly operator. The creation of the digital assembly folder is project-related, which means that a new folder is created for each new project.

To guarantee data consistency, it is necessary to retrieve information with links from SAP, other databases or drives used.

$\mathrm{FR}_{1.1}$ : Collect the right information for the production staff.

$\mathrm{FR}_{1.2}$ : Manage data changes.

$\mathrm{DP}_{1.1}$ : Digital assembly folder

$\mathrm{DP}_{1.2}$ : Version control system

The design matrix shows a decoupled matrix:

$$
\left\{\begin{array}{l}
\mathrm{FR}_{1,1} \\
\mathrm{FR}_{1,2}
\end{array}\right\}=\left[\begin{array}{ll}
\mathrm{X} & \mathrm{O} \\
\mathrm{X} & \mathrm{X}
\end{array}\right]\left\{\begin{array}{l}
\mathrm{DP}_{1,1} \\
\mathrm{DP}_{1,2}
\end{array}\right\}
$$

Since the FRs and corresponding DPs are not yet convertible into practice, a further decomposition process takes place. The subsequent FR-DP pairs and their design matrices are shown in the list below:

$\mathrm{FR}_{1.1 .1}$ : Capture ERP data.

$\mathrm{FR}_{1.1 .2}$ : Capture engineering design data.

$\mathrm{FR}_{1.1 .3}$ : Capture electrical design data.

$\mathrm{FR}_{1.1 .4}$ : Capture specifications.

$\mathrm{FR}_{1.1 .5}$ : Visualize the subcomponents.

$\mathrm{FR}_{1.1 .6}$ : Capture project-related information.

$\mathrm{FR}_{1.1 .7}$ : Illustrate the machinery.

$\mathrm{DP}_{1.1 .1}$ : Interface to ERP system (SAP).

$\mathrm{DP}_{1.1 .2}$ : Interface to design database/drawings.

$\mathrm{DP}_{1.1 .3}$ : Interface to electrical engineering database.

$\mathrm{DP}_{1.1 .4}$ : List of specifications.

$\mathrm{DP}_{1.1 .5}$ : Digital BOM (mechanics/electrics).

$\mathrm{DP}_{1.1 .6}$ : Project related documents.

$\mathrm{DP}_{1.1 .7}$ : Machinery pictures.
$\left\{\begin{array}{l}\mathrm{FR}_{1.1 .1} \\ \mathrm{FR}_{1.1 .2} \\ \mathrm{FR}_{1.1 .3} \\ \mathrm{FR}_{1.1 .4} \\ \mathrm{FR}_{1.1 .5} \\ \mathrm{FR}_{1.1 .6} \\ \mathrm{FR}_{1.1 .7}\end{array}\right\}=\left[\begin{array}{ccccccc}\mathrm{X} & 0 & 0 & 0 & 0 & 0 & 0 \\ \mathrm{X} & \mathrm{X} & 0 & 0 & 0 & 0 & 0 \\ \mathrm{X} & 0 & \mathrm{X} & 0 & 0 & 0 & 0 \\ \mathrm{X} & 0 & 0 & \mathrm{X} & 0 & 0 & 0 \\ \mathrm{X} & 0 & 0 & 0 & \mathrm{X} & 0 & 0 \\ \mathrm{O} & 0 & \mathrm{X} & 0 & \mathrm{X} & \mathrm{X} & 0 \\ 0 & 0 & 0 & 0 & 0 & 0 & \mathrm{X}\end{array}\right]\left\{\begin{array}{l}\mathrm{DP}_{1.1 .1} \\ \mathrm{DP}_{1.1 .2} \\ \mathrm{DP}_{1.1 .3} \\ \mathrm{DP}_{1.1 .4} \\ \mathrm{DP}_{1.1 .5} \\ \mathrm{DP}_{1.1 .6} \\ \mathrm{DP}_{1.1 .7}\end{array}\right\}(5)$

$\mathrm{FR}_{1.2 .1}$ : Identification of deviations / changes.

$\mathrm{FR}_{1.2 .2}$ : Notification of deviations / changes.

$\mathrm{DP}_{1.2 .1}$ : Version administration.

$\mathrm{DP}_{1.2 .2}$ : Notification system.

$$
\left\{\begin{array}{l}
\mathrm{FR}_{1.2 .1} \\
\mathrm{FR}_{1.2 .2}
\end{array}\right\}=\left[\begin{array}{ll}
\mathrm{X} & \mathrm{O} \\
\mathrm{X} & \mathrm{X}
\end{array}\right]\left\{\begin{array}{l}
\mathrm{DP}_{1.2 .1} \\
\mathrm{DP}_{1.2 .2}
\end{array}\right\}
$$

\subsubsection{FR2-DP2 Troubleshooting}

The second branch of the design tree ("Troubleshooting") provides a structured way of capturing, returning and evaluating problems throughout the assembly process. This process is mapped digitally via a workflow system integrated in the shop floor information system.

$\mathrm{FR}_{2.1}$ : Record problems / modifications during the assembly process.

$\mathrm{FR}_{2.2}$ : Allocate problems/modifications during the assembly process.

$\mathrm{FR}_{2.3}$ : Analyse problems/modifications during the assembly process.

$\mathrm{DP}_{2.1}$ : Input system.

$\mathrm{DP}_{2.2}$ : Allocation system.

$\mathrm{DP}_{2.3}$ : Evaluation process (Quality Management).

The design matrix shows a decoupled matrix:

$$
\left\{\begin{array}{l}
\mathrm{FR}_{2.1} \\
\mathrm{FR}_{2.2} \\
\mathrm{FR}_{2.3}
\end{array}\right\}=\left[\begin{array}{lll}
\mathrm{X} & \mathrm{O} & \mathrm{O} \\
\mathrm{X} & \mathrm{X} & 0 \\
\mathrm{X} & \mathrm{X} & \mathrm{X}
\end{array}\right]\left\{\begin{array}{l}
\mathrm{DP}_{2.1} \\
\mathrm{DP}_{2.2} \\
\mathrm{DP}_{2.3}
\end{array}\right\}
$$

Similar to the first FR-DP pair also here a further decomposition was executed. The results are the following:

$\mathrm{FR}_{2.1 .1}$ : Visualize problems / modifications

$\mathrm{FR}_{2.1 .2}$ : Describe problems / modifications

$\mathrm{DP}_{2.1 .1}$ : Camera function

$\mathrm{DP}_{\text {2.1.2: }}$ Comment function

$$
\left\{\begin{array}{l}
\mathrm{FR}_{2.1 .1} \\
\mathrm{FR}_{2.1 .2}
\end{array}\right\}=\left[\begin{array}{ll}
\mathrm{X} & \mathrm{O} \\
\mathrm{X} & \mathrm{X}
\end{array}\right]\left\{\begin{array}{l}
\mathrm{DP}_{2.1 .1} \\
\mathrm{DP}_{2.1 .2}
\end{array}\right\}
$$

\subsubsection{FR3-DP3 Communication System}

Further, the shop floor information system consists of an alternative communication tool to the previously used email. This communication tool aims to exchange information, modifications and news as quickly and easily 
as possible. The communication takes place project specifically.

$\mathrm{FR}_{3.1}$ : Represent the communication history.

$\mathrm{FR}_{3.2}$ : Attach files.

$\mathrm{FR}_{3.3}$ : Schedule appointments.

$\mathrm{FR}_{3.4}$ : Prioritize messages.

$\mathrm{DP}_{3.1}$ : Chat history.

$\mathrm{DP}_{3.2}$ : Cloud / server system.

$\mathrm{DP}_{3.3}$ : Scheduling system.

$\mathrm{DP}_{3.4}$ : Prioritization system.

The design matrix shows a decoupled matrix:

$$
\left\{\begin{array}{l}
F_{3.1} \\
F_{3.2} \\
F_{3.3} \\
F_{3.4}
\end{array}\right\}=\left[\begin{array}{llll}
\mathrm{X} & 0 & 0 & 0 \\
X & X & 0 & 0 \\
X & 0 & X & 0 \\
X & 0 & X & X
\end{array}\right]\left\{\begin{array}{l}
\mathrm{DP}_{3.1} \\
\mathrm{DP}_{3.2} \\
\mathrm{DP}_{3.3} \\
\mathrm{DP}_{3.4}
\end{array}\right\}
$$

\subsubsection{FR4-DP4 Monitoring Working Hours}

The shop floor information system consists also of a monitoring system for the working hours. This system simplifies the recording of processing's times, by entering them directly from a mobile device in the shop floor. In a next step the digital consigned processing times can be used for evaluation and analysis.

$\mathrm{FR}_{4.1}$ : Record processing times during the assembly process.

$\mathrm{FR}_{4.2}$ : Evaluate processing times in the assembly process

$\mathrm{DP}_{4.1}$ : Timekeeping system.

$\mathrm{DP}_{4.2}$ : Statistical evaluation tool.

The design matrix shows a decoupled matrix:

$$
\left\{\begin{array}{l}
\mathrm{FR}_{4.1} \\
\mathrm{FR}_{4.2}
\end{array}\right\}=\left[\begin{array}{ll}
\mathrm{X} & \mathrm{O} \\
\mathrm{X} & \mathrm{X}
\end{array}\right]\left\{\begin{array}{l}
\mathrm{DP}_{4.1} \\
\mathrm{DP}_{4.2}
\end{array}\right\}
$$

\subsubsection{FR5-DP5 Graphical User Interface}

The last branch of the design tree deals with the graphical visualization of the information in the shop floor information system. To ensure the most ergonomic and intuitive design of the information, the system has a graphical user interface (GUI) for each type of user.

$\mathrm{FR}_{5.1}$ : Present the correct information for production.

$\mathrm{FR}_{5.2}$ : Present the correct information for production management.

$\mathrm{FR}_{5.3}$ : Present the correct information for technical departments.

$\mathrm{FR}_{5.4}$ : Present the correct information for QM.

$\mathrm{DP}_{5.1}$ : GUI for digital assembly folder (production).

$\mathrm{DP}_{5.2}$ : GUI for digital assembly folder (production management).

$\mathrm{DP}_{5.3}$ : GUI for technical departments,

$\mathrm{DP}_{5.4}$ : GUI for QM department.
The design matrix shows a decoupled matrix:

$$
\left\{\begin{array}{l}
\mathrm{FR}_{5.1} \\
\mathrm{FR}_{5.2} \\
\mathrm{FR}_{5.3} \\
\mathrm{FR}_{5.4}
\end{array}\right\}=\left[\begin{array}{llll}
\mathrm{X} & \mathrm{O} & \mathrm{O} & \mathrm{O} \\
\mathrm{X} & \mathrm{X} & \mathrm{O} & \mathrm{O} \\
\mathrm{X} & \mathrm{X} & \mathrm{X} & \mathrm{O} \\
\mathrm{X} & \mathrm{X} & \mathrm{X} & \mathrm{X}
\end{array}\right]\left\{\begin{array}{l}
\mathrm{DP}_{5.1} \\
\mathrm{DP}_{5.2} \\
\mathrm{DP}_{5.3} \\
\mathrm{DP}_{5.4}
\end{array}\right\}
$$

\section{Final Concept}

After the completed mapping process of FRs and DPs, the DPs are transferred to PVs. Due to the homogeneous and partly very specific DPs, it had to be determined after an extensive market research that there is no software solution that can fulfil all requirements. Therefore, the system was divided into three subordinate systems, which relate to a superior system. Figure 3 gives an overview of the proposed software solution.

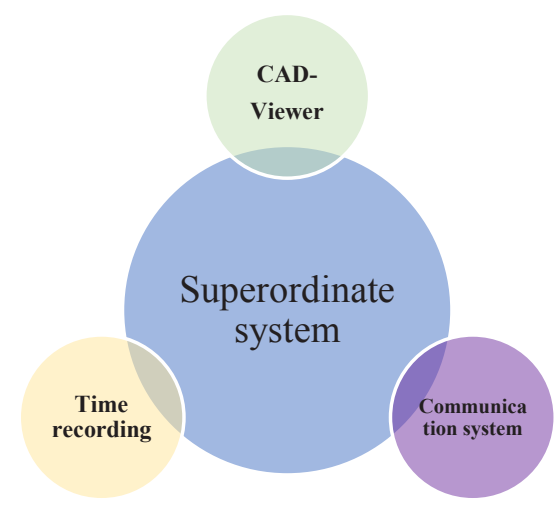

Figure 3: Software solution

The superordinate system must meet the requirements of $\mathrm{FR}_{1}-\mathrm{DP}_{1}$ Digital Assembly Folder, $\mathrm{FR}_{2}-\mathrm{DP}_{2}$ Troubleshooting and $\mathrm{FR}_{5}-\mathrm{DP}_{5}$ Graphical User Interface. $\mathrm{FR}_{3}-\mathrm{DP}_{3}$ Communication System is met by the communication system subsystem. The second subsystem supports the superordinate system in $\mathrm{FR}_{1}-\mathrm{DP}_{1}$ Digital Assembly Folder, by the visualization of CAD-drawings or explosion drawings and their change requests. The last subsystem Time recording fulfils the $\mathrm{FR}_{4}-\mathrm{DP}_{4}$ Monitoring Working Hours.

After carrying out a comprehensive technology research together with the technicians and the IT department of the case study company, the following systems best met the concept design:

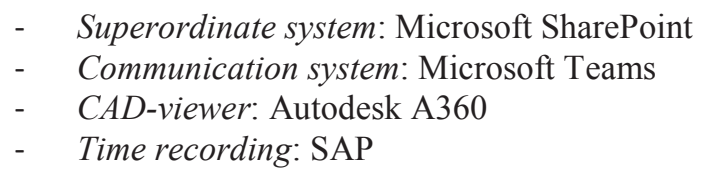

After selecting the different technologies, a first mock-up for the digital shop floor information system was developed. The mock-up served as a demonstration model, illustrating the main functions and the appearance of the product to employees of the engineering and quality management department and operators in production.

Figure 4 represents the main page of the digital shop floor information system for a mobile device. This main 
page provides an overview of the most important project information. The "Timeline Milestones" section shows the user if he is on schedule and when certain milestones need to be met. The "Project News" summarize important project-related information that all employees receive. The tiles shown in the lower area link to the individual folders of the assembly folder and the time recording. MS Teams is displayed in the lower right corner and is used for communications inside the project area.

\section{$<$ Project/ $><$ Project Number/>}

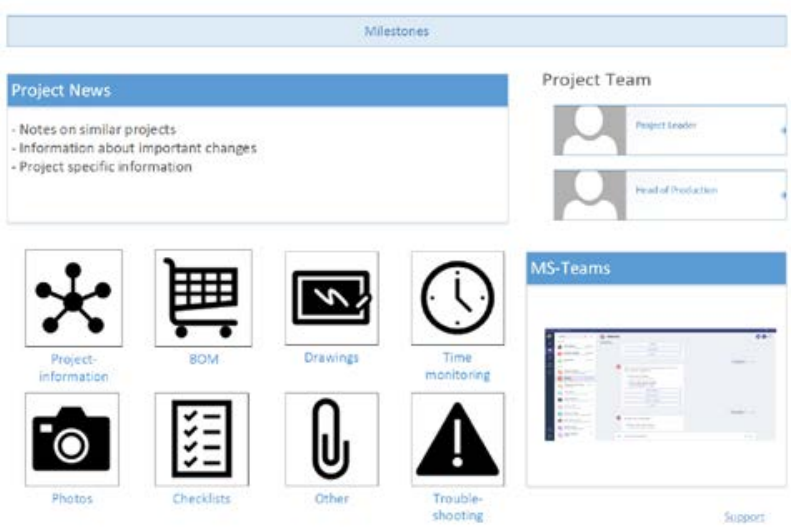

Figure 4: Main page of the digital shop floor information system

In the following a practical application case is presented to understand the functionality of the concept design in more detail.

An employee starts with the assembly of a component. All required parts should be contained in a pre-commissioned box. However, parts may still be missing for various reasons. The employee can use the Shop Floor Information System to track the status of the missing part in real time and react if necessary. In the classical approach, the employee has to visit the warehouse manager and check together with him where the part is located. In the further process of the assembly, it can occur that changes are made directly at the plant. Without the newly developed digital shop floor information system these changes are manually noted in the electrical plan and transferred from the technical office to the digital electrical plan. This procedure can lead to a loss of information. With the help of the new system, the employee can digitally draw the information onto the electrical plan and store it in a cloud, thus counteracting the loss of information. Further, after each completed task, the employee can register the hours worked directly from the digital shop floor management system, which improves continuous and consistent time recording.

\section{Conclusion and Outlook}

This work shows the design of a digital shop floor information system by using AD as development method. In the development process $\mathrm{AD}$ gave the developers a structured design approach, which made it possible to capture all necessary functions. AD was also helpful, as no software solution could be found for the implementation that would enable all functions. Due to the good basis of $\mathrm{AD}$, the designers could proceed in a structured way and find different software solutions for each branch of the design tree and merge them by a superordinate software.

In summary it can be said, that the application of AD made it possible to meet the software's initial objectives. Since a concept system was developed which improves the mutual communication between the departments via a shared IT system. This new system makes the processes more efficient by providing the right information, in the right place, for the right user to reduce lead time and reduce production costs.

The framework developed with $\mathrm{AD}$ was applied in a real industrial use case whose results were cited as mock-ups. These mock-ups show the key features and a rough look of the digital shop floor information system. Based on the mock-ups and the DPs defined in AD, the concept design can be adapted and applied also to other use cases. A certain focus of the development of the digital shop floor information system was always the simplicity and user-friendliness of the system, as this is the only way to take full advantage of the system especially in SMEs.

This project has received funding from the Free University of Bolzano under the grant agreement TN2079 (project title: Smart Shop floor - Development of a software prototype for intelligent Shop floor Management through Industry 4.0 technologies).

\section{References}

[1] B. Jürgen, „Erschließen der Potenziale der Anwendung von ,Industrie 4.0“ im Mittelstand,“ 2015.

[2] E. Rauch, P. Dallasega und D. T. Matt, ,The way from lean product development (LPD) to smart product development (SPD), “ Procedia CIRP, 50, pp. 26-31, 2016.

[3] B. Werner, „Warum Industrie 4.0 und Lean zwingend zusammengehören, “VDI-Z, pp. 46-47, November 2014.

[4] K. Dr. Lichtblau, V. Prof. Stich, R. Dr. Bertenrath, M. Blum, M. Bleider, A. Millack, K. Schmitt, E. Schmitz und M. Schröter, ,Industrie 4.0 Readniness, “ Aachen, Cologne, 2015.

[5] W. H. Kagermann, „Umsetzungsempfehlungen für das Zukunftsprojekt Industrie 4.0: Abschlussbericht," 2013.

[6] O. Dr. Drumm, R. Dr. Eckardt, A. Prof. Dr. Fay, G. Gutermuth, D. Krumsiek, U. Dr. Löwen, T. Makait, T. Mersch, A. Schertl, T. Schindler, M. Dr. Schleipen and S. Schröck, "VDI Statusreport: Durchgängiges Engineering in Industrie 4.0 Wertschöpfungsketten," VDI/VDEGesellschaft, 2016.

[7] D. T. Matt, M. Pichler und E. Rauch, „Collaboration Stream Mapping (CSM) - A method for improving enterprise knowledge management, "International Conference on Production Research, pp. 319-324, 2014. 
[8] "Definition of engineering," [Online]. Available: https://en.oxforddictionaries.com/definition/engi neering. [Accessed 15 April 2019].

[9] C. Hertle, J. Hambach, A. Meißner, S. Rossmann, M. J. und J. Rieger, „Digitales Shopfloor Management: Neue Impulse für die Verbesserung in der Werkstatt.," Productivity 22, pp. 59-61, 2017.

[10] D. Spath, O. Ganschar, S. Gerlach, T. Hämmerle und S. Schlund, „Produktionsarbeit der Zukunft," Industrie 4.0. Frauenhofer Verlag.

[11] E. Rauch, R. Rojas, P. Dallasega and D. T. Matt, "Smart Shopfloor Management: Anforderungen an ein digitales und intelligentes Shopfloor Management im Zeitalter von Industrie 4.0," $Z W F$, pp. 17-21, 2018.

[12] T. Bauernhansl, M. ten Hompel und B. VogelHeuser, Industrie 4.0 in Produktion, Automatisierung und Logistik: Anwendung, Technologien, Migration., Wiesbaden: Springer Vieweg, 2014.

[13] "Smarter dank MES," SCOPE Industriemagazin für Produktion, p. 58, 2016.

[14] K. M. Eisenhardt, "Building Theory From Case Study Research," The Academy of Management Review, pp. 532-550, October 1989.

[15] N. P. Suh, Axiomatic Design: Advances and Applications, New York: Oxford University Press, 2001.

[17] E. Rauch, P. R. Spena and D. T. Matt, "Axiomatic design guidelines for the design of flexible and agile manufacturing and assembly systems for SMEs," International Journal on Interactive Design and Manufacturing (IJIDeM), pp. 1-22, 6 März 2018.

[18] S. Cochran, J. Arinez, J. W. Guda, J. Linck, “A decomposition approach for manufacturing system design", International Journal of Manufacturing Systems, Vol. 20, No. 6, pp. 371389, 2001. 